\title{
Accident prevention
}

\section{Maconochie}

\section{A priority for paediatricians}

$\mathrm{T}$ rauma prevention is a neglected area from the point of view of coordinated input by paediatricians at local level and to an extent at the Royal College of Paediatrics and Child Health ( $\mathrm{RCPCH})$ level. This oversight is surprising given that injury to children is associated with considerable morbidity and mortality. Part of the difficulty generating interest in trauma prevention may lie in the relatively intangible benefits of reducing injury, but nonetheless every paediatrician should consider it within their remit to take any opportunity to reduce accidents which account for over one third of all deaths up tol9 years of age. Injury prevention schemes can be cost effective provided they are well directed with achievable goals. ${ }^{1}$

Effective injury prevention depends on a combination of three areas of implementation: education, alteration of environmental hazard, and the enforcement of safety legislation. Paediatricians can be involved in improving all the elements of injury prevention: primary prevention (prevention of the accident; for example, using safe materials in playground $\mathrm{s}^{2}$ ); secondary prevention (reducing the effects from the accident; for example, promoting the wearing of bicycle helmets $\left.{ }^{3}\right)$; and tertiary prevention (diminishing the consequences of the event by the effectiveness of the emergency services provided after the accident). The latter aim can be achieved by improving resuscitation training for dealing with critically ill children by teaching courses such as Paediatric Advanced Life Support (PALS), ${ }^{4}$ Advanced Paediatric Life Support (APLS), the Advanced Trauma Life Support course (ATLS), ${ }^{6}$ and Prehospital Paediatric Life Support Courses.

Table 1 Causes of deaths in boys and girls in 1999 (published by the Office for National Statistics, www.statistics.gov.uk)

\begin{tabular}{lllll}
\hline & \multicolumn{4}{l}{ Age of boys/girls } \\
\cline { 2 - 5 } & $1-4$ & $5-9$ & $10-14$ & $15-19$ \\
\hline All causes & $306 / 241$ & $141 / 111$ & $176 / 117$ & $555 / 267$ \\
Trauma (includes poisoning) & $61 / 47$ & $30 / 22$ & $67 / 28$ & $329 / 114$ \\
Infection & $31 / 26$ & $7 / 5$ & $5 / 5$ & $18 / 20$ \\
Neoplasms & $42 / 30$ & $46 / 30$ & $39 / 17$ & $53 / 34$ \\
CNS disease & $44 / 31$ & $20 / 20$ & $21 / 23$ & $38 / 23$ \\
Respiratory disease & $29 / 17$ & $9 / 11$ & $9 / 11$ & $15 / 13$ \\
Circulatory disease & $15 / 20$ & $2 / 7$ & $10 / 6$ & $16 / 13$ \\
\hline
\end{tabular}

public health strategy for England (www.ohn.gov.uk). It was published in July 1999 with the two laudable aims of improving health and reducing the health gap (that is, health inequalities) within England. Four disease processes have been targeted: cancer, coronary heart disease, mental health, and accidents. The target for accidents is: "the reduction in death rates by at least one fifth and to reduce the rate of serious injury by at least one tenth by $2010^{\prime \prime}$, so saving up to 12000 lives.

The Department of Health set up the Accidents and Accidental Injury Task Force. Its terms of reference were to advise the Chief Medical Officer on:

(1) The most important priorities for immediate action in order to meet the (White Paper) target

(2) The development of an implementation plan, consulting with other stakeholders where necessary

(3) Whether the necessary delivery structures are in place to forward the implementation plan

(4) How progress on the implementation plan should be monitored

(5) How to develop and publicise a more unified approach to accident prevention across the government and the NHS.

It had been expected to report its findings in December 2001

The OHN paper has launched a raft of iniatives aimed at reducing accidents involving other departments of government; these include "Safe routes to schools and healthy citizens programme" (directed at minimising the effects of accidents though the skills programme for 14-16 year olds), "Hedgehogs—child road safety" (aimed at 7-12 year olds), "THINK! Road safety", and also "Fire kills-you can prevent it". The latter three campaign details are located on the Department for Transport, Local Government and the Regions Safety pages (www.dltr.gov.uk). Other governmental departments provide useful information on their user friendly websites (see the appendix). These sites provide useful points of reference to local initiatives that can be undertaken in conjunction with community health bodies, police, health promotion bodies, and other organisations such as the Royal Society of Prevention of Accidents, the Child Accident Prevention Trust, and the National Community Fire Safety Centre (www.community-firesafety.org.uk), as well as local authorities.

THE ROLE OF LOCAL AUTHORITIES IN INJURY PREVENTION

Local authorities have statutory duties regarding injury prevention and can be a 
valuable source of information. They have a legal requirement to reduce traffic accidents and have duties regarding trading standards, environmental health, and educational roles in accident prevention.

There is a great deal of expertise within local authorities: environmental health officers, road safety officers, trading standards officers, community fire and police officers, youth workers, and workers in childcare and community development sectors all have an impact on decreasing the burden of trauma.

\section{THE ROLE OF THE VOLUNTARY SECTOR IN INJURY PREVENTION}

There are many voluntary national bodies that can assist in the three areas of injury prevention. These include the Child Accident Prevention Trust, the Royal Society for the Prevention of Accidents, and Trauma Care; their websites provide links to other key players in these areas. These three bodies can provide information and support for paediatricians and other healthcare professionals interested in primary, secondary, or tertiary prevention strategies.

\section{Child Accident Prevention Trust (www.capt.org.uk)}

Two paediatricians, Dr Hugh Jackson and Professor Donald Court, formed a committee in the late 1970s to focus on child accident prevention, which became the Child Accident Prevention Trust (CAPT) in 1981.This charity is committed to reducing childhood injury and supports local coalitions of families, health professionals, and organisations in making communities safer for children under their "SAFEKIDS" campaign.

Every year CAPT holds a Child Safety Week (in 2003 it commences on 23 June). This week has a number of aims, including providing clear safety information to the public, persuading local communities to take part in child safety activities, and encouraging the media to give positive coverage to child injury prevention and safety issues. CAPT has produced a planning kit to help organise activities around the theme of accident prevention. This can be directly downloaded from the website.

\section{Royal Society for the Prevention of} Accidents (www.rospa.co.uk)

This charitable organisation provides information, advice, resources, and training, and promotes safety in all areas of life.

\section{Traumacare UK}

\section{(www.traumacare.org.uk)}

This is a multidisciplinary charitable organisation. It includes healthcare professionals who have contact with the consequences of trauma, from those who work in the prehospital phase of trauma, to those who are hospital based, and those involved in the rehabilitation of the injured patient. The central tenet is the seamless transition of care from the arrival of the first professional in contact with the injured patient to the last healthcare worker. Traumacare UK focuses on improving tertiary prevention and has produced a manual of trauma management in the UK. This organisation holds biannual conferences covering all aspects of trauma and acts as a forum for professionals from different backgrounds to meet and discuss problems that they face in looking after the injured patient.

\section{EDUCATION}

Education combined with directed environmental change comprises the keystones of injury prevention. The importance of the educational aspects of injury prevention has been illustrated by the Department for Education and Skills which published good practice guidance in December 2001 with the aim of increasing the amount of safety education taught within schools (www.teachernet.gov.uk/bank/Safety Guidance leaflet2.pdf).

Attitudes to safe behaviour can be taught as part of the National Curriculum. The Injury Minimisation Programme for Schools (IMPS) (Www. impsweb.co.uk) includes an education pack with accident prevention lessons based on the National Curriculum, and a hospital visit including first aid training and a tour of the local A\&E department. Five months after the programme, children are more likely to identify subtle dangers, are more likely to seek help, and to tell others that their behaviour is dangerous. ${ }^{10}$ Paediatricians can actively support this programme by contacting IMPS. Currently this programme is active in 13 centres in England and is actively seeking more locations throughout the UK.

\section{HOSPITAL BASED WORK IN INJURY PREVENTION}

The home, roads, playgrounds, and sporting arenas have risks which can be reduced by environmental and behavioural changes; wearing bicycle helmets, for example, reduces by $63-88 \%$ the risk of head, brain, and severe brain injury for all ages of cyclists. ${ }^{11}$

Local initiatives involving hospital based paediatricians in the UK have had an impact in these areas-for example, the work on bicycle helmet use ${ }^{1213}$ and on playground safety ${ }^{14}{ }^{15}$ has led to a better understanding of the effects of altering the environment and on implementing advances in the design.
Another hospital based scheme is the Gloucestershire Home Safety Check and Herefordshire Home Check (www. homesafety.co.uk). This is based at the Health Promotion Unit at Gloucestershire Royal Hospital and represents a collaboration with local health authorities, Health Trusts, voluntary and nonstatutory groups, and neighbourhood and community groups. It offers home safety visits, repairs and rectifications, smoke detector fitting, and child safety services.

\section{WHAT PAEDIATRICIANS CAN DO AT A LOCAL LEVEL}

Paediatricians may wish to form local networks with their other hospital based colleagues, and with the local authorities and community services. Healthcare professionals such as general practitioners, health visitors, school nurses, community nurses, and managers, combined with heads of schools, playgroup leaders, and local media can form a powerful alliance to launch injury prevention schemes.

An example of a local prevention initiative, in conjunction with A\&E colleagues, is the routine collection of data relating to injuries attending A\&E. These data can, for example, identify areas frequently associated with injury and lead to effective safety changes in road design in "accident blackspots" by liaising with local police and the local authority. Similarly, types of frequently occurring domestic injuries can lead to targeted local campaigns.

Any such campaign which has an educational element needs to be designed with its audience in mind. Teenagers can very effectively teach one another; the same message from an "old fogey" (that is, anyone over the age of 20 years!) may not be assimilated as well. ${ }^{16}$ The RCPCH can also be supportive in local initiatives.

\section{WHAT CAN THE RCPCH DO?}

The RCPCH can be more active in supporting injury prevention by the following:

(1) Establishing Trauma Fellowships which would allow trainees and seniors to develop the necessary skills to research the causes of injury and establish effective interventions, and help in develop prevention strategies on a local or national scale.

(2) Showing more overt support of CAPT activities; yearly initiatives with CAPT could be developed and the membership of the RCPCH be encouraged to take part. Such activities could count towards continuous professional development (CPD) and awards be given to examples of 
particularly good working partnerships, so encouraging prevention work

(3) Providing a database of injury prevention activities involving members; they could briefly describe their work on the BPSU monthly return card, along with their contact details.

(4) Currently the BPSU does collect information regarding nonaccidental abdominal injuries; its remit could be widened to study a particular form of injury and then, with the support of other agencies, study the effect of injury prevention strategies on a national basis.

The last RCPCH based meeting on paediatric accidents was in 1991; one of the authors of the publication of the meeting held under the auspices of the Royal College of Physicians was the current President Elect of the RCPCH, Professor Alan Craft. He wrote in the opening chapter "Improvements in accident rates will be slow and will come about as a result of environmental change by education. Both are needed, but the education needs to be correctly targeted. The doctor undoubtedly has a role to play in this change." ${ }^{\prime 7}$

Accident prevention needs paediatricians being involved at local level and for the RCPCH to appear more active in injury prevention.

\section{APPENDIX}

The Department of Trade and Industry website (www.dti.gov.uk) provides advice on regulatory guidance, consumer protection, environmental issues, and product safety, as well as containing the home safety network.

Other helpful government websites include the Health and Safety Executive (www. hse.gov.uk) and the Health Development Agency (www.had-online.org.uk) which comes under the Department of Health (www.doh.gov.uk).

The Scottish Executive and National Assembly also have a wealth of informative sites which can be accessed via www.scotland.gov.uk and www.wales.gov.uk.

Arch Dis Child 2003;88:275-277

\section{Authors' affiliations}

I Maconochie, Department of Paediatric Emergency Medicine, St Mary's Hospital, London, UK

Correspondence to: Dr I Maconochie, Department of Paediatric Emergency Medicine St Mary's Hospital, South Wharf Road, London W2 1NY, UK; i.maconochie@ic.ac.uk

\section{REFERENCES}

1 Miller TR, Levy DT. Cost-outcome analysis in injury prevention and control: eighty-four recent estimates for the United States. Medical Care 2000;38:562-82.

2 Norton C, Morris S, Jones MD, et al. Have modern safety changes to playgrounds reduced head injury and fracture to children? [G69 abstract]. RCPCH meeting, York, April 2002.

3 Mann NP, Lee AJ. Bicycle helmets: their role in injury prevention. Curr Paediatr 1999;9:173-6
4 PALS. Paediatric Advanced Life Support. Course material. American Heart Association, c/o UK Resuscitation Council, UK.

5 APLS. Advanced Paediatric Life Support. Course material. Advanced Life Support Group, 2nd edn. London: BMU Books, 2002.

6 ATLS. Advanced Trauma Life Support course. Course material. Advanced Trauma Life Support Instructor Manual, 6th edn. American College of Surgeons, 1997.

7 Advanced Life Support Group. Pre-hospital Paediatric Life Support. Course material. London: BM Books, 2001

8 Department of Trade and Industry. Home and leisure accident report: summary of 1998 data. London: DTI Publications, 1998.

9 Children Accident Prevention Trust. Website. http//www.capt.org.uk.

10 Frederick K, Bixby E, Orzel MN, et al. An evaluation of the effectiveness of the Injury Minimization Programme for Schools (IMPS) Injury Prevention 2000;6:92-5.

11 Thompson DC, Rivara FP, Thompson R. Helmets for preventing head and facial injuries in bicyclists (Cochrane Review). In: The Cochrane Library, Issue 2. Oxford: The Cochrane Library, Iss
Update Software, 2002.

12 Lee AJ, Mann NP, Takriti R. A hospital led promotion campaign aimed to increase cycle helmet wearing amongst $11-15$ year olds in West Berkshire. Injury Prevention 2000;6:151-3.

13 Takriti R, Lee AV, Mann NP. Teenage attitudes to cycle helmets. Health Educ 2000; 101:169-75.

14 Mott A, Evans, Rolfe K, et al. Patterns of injuries to children on public playgrounds. Arch Dis Child 1994;71:328-30.

15 Mott A, Rolfe K, James R, et al. Safety of surfaces and equipment for children in playgrounds. Lancet 1997;14:316-20.

16 Harden A, Weston R, Oakley A. A review of the effectiveness and appropriateness of peer-led promotions interventions for young people. London: Evaluation of Health Promotion and Social Interventions, 1999: 1-180.

17 Sibert J, ed. Accidents and emergencies in childhood. London: Royal College of Physicians, 1992

\section{IMAGES IN PAEDIATRICS}

\section{Cloacal exstrophy}

T

his newborn baby was referred to us for malformed lower abdomen since birth. On examination the umbilical cord

was displaced downward and the lower abdominal wall was replaced by a large red coloured mass. The mass had a thin, red, protruding tubular structure in the middle resembling an elephant trunk, and five visible orifices. External genitalia could not be identified (fig). A diagnosis of cloacal exstrophy was made.

Cloacal exstrophy is the rarest and most extreme form of the exstrophy-epispadias complex that occurs once in 200000 to 400000 births. ${ }^{1}$ Embryologically four separate foldscephalic, caudal, and right and left lateral-each of which has a splanchnic and somatic aspect, form the anterior abdominal wall. Failure of the caudal fold to close results in cloacal exstrophy. ${ }^{2}$ Classically it consists of an exstrophic central bowel field flanked by two hemi-bladders. Omphalocoele is present in $90 \%$ of cases. There are 3-4 orifices in the central bowel field, which is an ileocaecal region. The proximal orifice leads to the terminal ileum, which often prolapses, producing an elephant trunk deformity. The distal orifice leads to a short, blind ending colon segment. One or more appendiceal orificesmay be present. The anus is imperforate, and external genitalia have a wide range of anomalies, including absent penis/clitoris, absent scrotum, epispadias, hemiscrota, etc. ${ }^{1}$

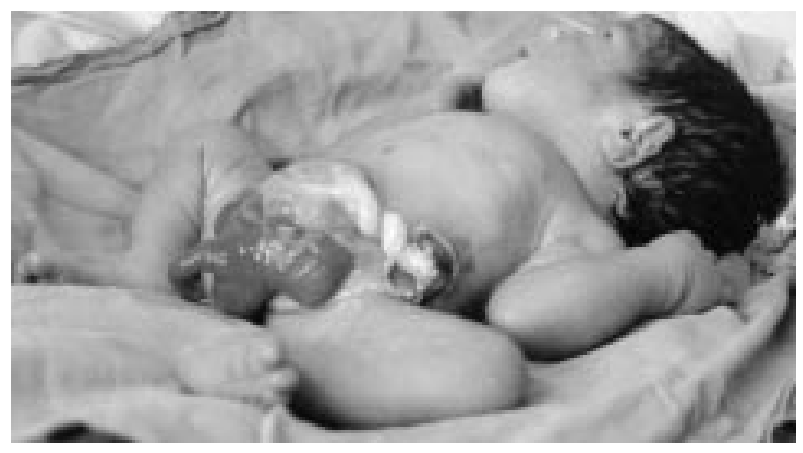

R A Reddy, B Bharti, S C Singhi Dept of Pediatrics, Advanced Pediatrics Centre, PGIMER, Chandigarh, V. India; drsinghi@glide.net.in

\section{References}

1 Manzoni GM, Hurwitz RS. Cloacal exstrophy. In: Freeman NV, Burge DM, Griffiths M, Malone PSJ, eds. Surgery of the newborn. Edinburgh: Churchill Livingstone, 1998:767-80.

2 Davis CF, Young DG. Congenital defects and surgical problems. In Rennie JM, Roberton NRC, eds. Textbook of neonatology, 3rd edn. Edinburgh: Churchill Livingstone, 765-93. 